\title{
Parameters Associated with Risk of Cirrhosis at Diagnosis of Autoimmune Hepatitis in Children
}

\author{
Ibrahim A Elhenawy ${ }^{1}$, Heba Samy Ghanem ${ }^{2}$ and Mostafa Mohamed Sira ${ }^{1 *}$ \\ ${ }^{1 D}$ epartment of Pediatric Hepatology, Gastroenterology and Nutrition, National Liver Institute, Menofiya University, Egypt \\ ${ }^{2}$ Department of Clinical Pathology, National Liver Institute, Menofiya University, Egypt
}

Submission: February 09, 2017; Published: April 11, 2017

"Corresponding author: Mostafa M Sira, Department of Pediatric Hepatology, Gastroenterology and Nutrition, National Liver Institute, Menofiya University, 32511 Shebin El-koom, Menofiya, Egypt, Tel: +2-048-222-2740; Fax: +2-048-223-4586; Email: msira@liver-eg.org

\begin{abstract}
Background: Autoimmune hepatitis (AIH) is a serious chronic and progressive disease. At least a third of patients have cirrhosis at presentation. Patients with cirrhosis at diagnosis have a poorer prognosis than those without.
\end{abstract}

Aim: We aimed to identify parameters associated with risk of cirrhosis at diagnosis of AIH.

Methods: This prospective study included 68 children with AIH. Liver biopsy was performed for all the patients. Hepatic fibrosis and necroinflammation were evaluated according to Ishak score. Patients with Ishak fibrosis score 5 and 6 (incomplete and complete cirrhosis respectively) were compared to the other patients with Ishak score $\leq 4$.

Results: Children age ranged between 1.5 years to 16 years. They were 42 females and 26 males. Seventeen (25\%) had cirrhosis. Patients with cirrhosis at presentation had higher mean age (10.12 years vs. 7.89 years) and were mainly of female sex ( $82.4 \%$ vs. $54.9 \%)$. Splenomegaly was more frequent in those with cirrhosis $(\mathrm{P}=0.048)$. They also had lower serum albumin $(\mathrm{P}=0.039)$, longer prothrombin time $(\mathrm{P}=0.04)$, lower platelets count $(P=0.001)$ and higher serum gammaglobulins $(P=0.027)$. Female sex, splenomegaly, age $\geq 9.5$ years, albumin $\leq 3 \mathrm{gm} / \mathrm{dl}$, prothrombin time $\geq 14$ seconds, platelets count $\leq 200 \times 10^{3} / \mathrm{mm}^{3}$, and gammaglobulins $>2.26 \mathrm{gm} / \mathrm{dl}$ were associated with relative risk of cirrhosis ranging between 2.1 and 4.9 .

Conclusion: Care should be given to children with AIH who have parameters associated with relative risk of cirrhosis at diagnosis as they may need rapid and more aggressive immunosuppressive therapy to improve the outcome.

Keywords: Autoimmune hepatitis; Children; Cirrhosis; Liver biopsy; Relative risk

Abbreviations: AIH: Autoimmune Hepatitis; ANA: Anti-Nuclear Antibody; AMA: Anti-Mitochondrial Antibody; ASMA: Anti-Smooth Muscle Antibody; ELISA: Enzyme Linked Immunosorbent Assay; NA: Not Available; Type 1 LKM-1: Liver-Kidney Microsomal Antibody Type 1; PT: Prothrombin Time

\section{Introduction}

Autoimmune hepatitis (AIH) is a serious chronic and progressive disease characterized by histological interface hepatitis, hypergammaglobulinemia, circulating autoantibodies and a favorable response to immunosuppressive drugs [1,2]. Timely diagnosis and early immunosuppressive therapy is life-saving to hamper progressive destruction of the liver parenchyma and limit the development of progressive fibrosis and cirrhosis [3]. AIH has a female predominance. It occurs in children and adults of all ages and affects several ethnic groups [4]. In general, the clinical spectrum of AIH ranges from asymptomatic to severe, with variable symptoms of liver affection $[5,6]$.

The presence of specific antibodies to particular liver autoantigens is one of the core diagnostic criteria of AIH and its subtypes. AIH type 1 has been characterized by the presence of anti-nuclear (ANA) and/or anti-smooth muscle antibodies (ASMA), whereas liver/kidney microsomal antibodiy type 1 (LKM-1) have been considered as the hallmark of AIH type 2 [7].

Histologically AIH is characterized by prominent lymphocytic infiltration and varying degrees of lobular hepatitis [8]. At least a third of patients have already cirrhosis at presentation, indicating that the disease has gone unrecognized for a considerable period of time prior to diagnosis [9]. Corticosteroid therapy must be 
instituted early despite the absence of symptoms [10]. The rapidity of improvement rather than the severity of inflammation may be important in preventing disease progression in mild disease, and protection can be most reliably obtained by instituting treatment [11].

Patients with cirrhosis and those with bridging necrosis at diagnosis have a poorer prognosis than those without $[12,13]$. The aim of the current study is to identify parameters associated with the risk of cirrhosis at the initial liver biopsy at diagnosis of AIH. Patients and Methods

\section{Study population}

This prospective study included 68 children with AIH recruited from the Pediatric Hepatology, Gastroenterology and Nutrition department, National Liver Institute, Menofiya University. Autoimmune hepatitis (AIH) group: defined by elevated transaminases, hypergammaglobulinemia and/or presence of non-specific autoantibodies, absence of any other etiology and supported by the histopathological feature of AIH in liver biopsy; according to the international scoring system [14]. Inclusion criteria were male or female patients with AIH up to the age of 18 years. Liver biopsy was mandatory for inclusion in the study. Patients with associated liver disease or other immunologic disorders and those with uncorrected coagulopathy or with contraindication to liver biopsy were excluded from the study. The study was approved by the Research Ethics Committee of National Liver Institute, Menofiya University.

\section{Serum autoantibodies and protein electrophoresis}

All patients and controls were tested for serum autoantibodies and gammaglobulins at presentation. ANA, ASMA, LKM-1, and antimitochondrial antibody (AMA) were tested by indirect immunofluorescence technique using a Fluoro-KitTM Combo Pak (All from DiaSorin, Minnesota, U.S.A.). Protein electrophoresis was performed using Titan III Cellulose Acetate Plate and scanned using Helena QuickScan 2000.

\section{Serum viral markers, ultrasonography and liver biopsy}

Hepatitis B surface antigen (HBsAg), anti-hepatitis B core IgM and IgG types, were tested for by enzyme linked immunosorbent assay (ELISA) kit (All from Sorin Biomedica Co, Spain). Hepatitis A antibody immunoglobulin (Ig)M was tested by ELISA (Diapro diagnostic bioprobes, Italy). Hepatitis C virus antibody (anti-HCV) was tested by $4^{\text {th }}$ generation ELISA (Innogenetics, Ghent-Belgium).
Real-time polymerase chain reaction for HCV-RNA was performed using COBAS $₫$ Ampliprep/COBAS $₫$ TaqMan $\AA$, Roche Molecular Systems, Inc., Branchburg, NJ, 08876 USA. Ultrasonography (US) was performed by using 2-5-MHz curved linear and 4-8-MHz linear transducers (Xario XG; Toshiba, Tokyo Japan). Liver biopsy was performed for all the patients using an US guided Tru-cut needle. Hepatic necroinflammatory activity and liver fibrosis were evaluated according to Ishak score [15]. Patients with Ishak fibrosis score 5 and 6 (incomplete and complete cirrhosis respectively) were compared to the other patients with fibrosis of Ishak fibrosis $\leq 4$.

\section{Statistical analysis}

Values were expressed as mean \pm standard deviation (mean \pm SD) or number (percentage) of individuals with a condition. For quantitative data, statistical significance was tested by either independent samples t-test or by the non-parametric MannWhitney $U$ test according to the nature of the data. For qualitative data, significance was tested by Chi-square test or Fisher's exact test. Correlation was tested by Spearman's test. The cutoff values for the significant risk factors were determined from the receiveroperating characteristic (ROC) curves. Relative risk was calculated from complex samples crosstabs statistics. Results were considered significant if P-value $<0.05$. Statistical analysis was performed using SPSS, version 13 (SPSS Inc, Chicago, IL, USA).

\section{Results}

\section{Study population characteristics}

The current prospective study included 68 children with AIH. Their ages ranged between 1.5 years to 16 years. They were 42 females and 26 males with female preponderance of a ratio of 2.6. Fifty-three (77.9\%) children were type $1 \mathrm{AIH}$, only one child $(1.5 \%)$ was of type $2 \mathrm{AIH}$, and 14 children (20.6\%) were seronegative for the studied conventional autoantibodies. All children had liver biopsy performed at presentation, 17 (25\%) of them had cirrhosis.

\section{Correlation of the studied parameters with liver fibrosis}

All patients, at certain degree, had fibrosis or cirrhosis at presentation. Age, prothrombin time (PT) and gammaglobulins correlated directly with fibrosis while serum albumin and platelets negatively correlated with fibrosis (Table 1 \& Figure 1). There was no significant correlation with the other studied laboratory parameters.

Table 1: Correlation of liver fibrosis with age and laboratory parameters of the studied patients.

\begin{tabular}{|c|c|c|}
\hline \multirow{2}{*}{ Parameter } & \multicolumn{2}{|c|}{ Liver Fibrosis } \\
\cline { 2 - 3 } & $\mathbf{2}$ & P-value \\
\hline Age (years) & 0.3 & 0.013 \\
\hline Total bilirubin (mg/dl) & 0.091 & 0.464 \\
\hline Direct bilirubin (mg/dl) & 1 & 0.418 \\
\hline Albumin (g/dl) & -0.363 & 0.002 \\
\hline
\end{tabular}




\section{Advanced Research in Gastroenterology \& Hepatology}

\begin{tabular}{|c|c|c|}
\hline Alanine aminotransferase (U/L) & -0.081 & 0.51 \\
\hline Aspartate aminotransferase (U/L) & -0.042 & 0.738 \\
\hline Alkaline phosphatase (U/L) & -0.026 & 0.839 \\
\hline gamma-glutamyl transpeptidase (U/L) & -0.016 & 0.896 \\
\hline Prothrombin time (seconds) & 0.357 & 0.003 \\
\hline Hemoglobin (g/dl) & -0.12 & 0.129 \\
\hline White blood cells $\left(\mathrm{x} 10^{3} / \mathrm{mm}^{3}\right)$ & -0.186 & $<0.0001$ \\
\hline Platelets $\left(\mathrm{x} 10^{3} / \mathrm{mm}^{3}\right)$ & -0.477 & 0.037 \\
\hline Gammaglobulins $(\mathrm{g} / \mathrm{dl})$ & 0.253 & \\
\hline
\end{tabular}
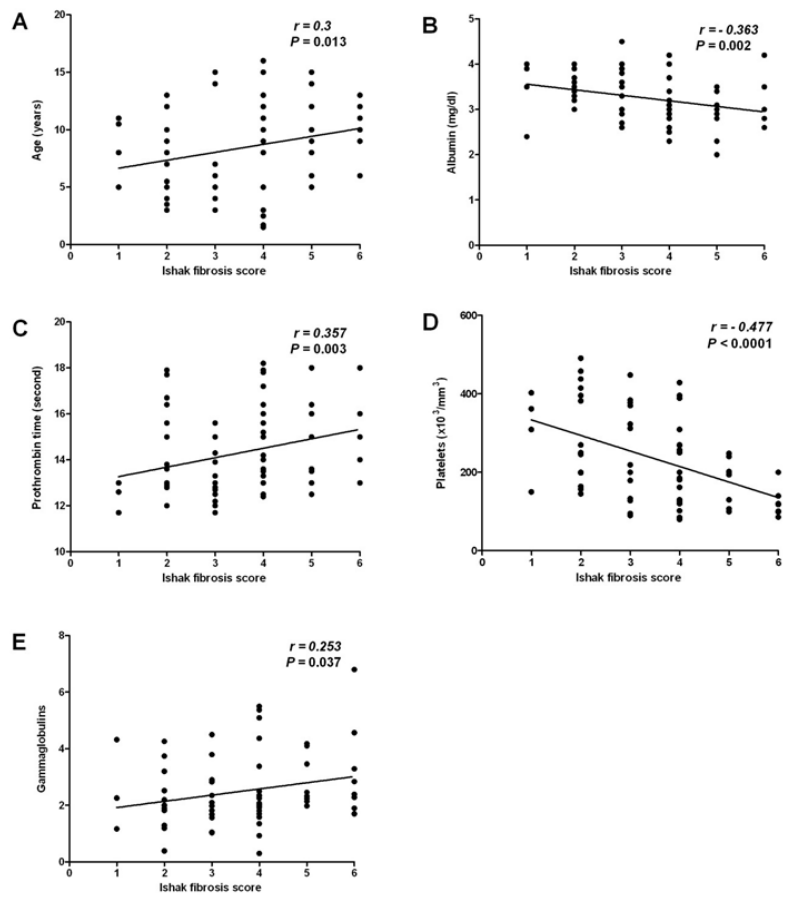

Figure 1: Correlation of age and laboratory parameters with liver fibrosis.

Table 2: Demographic, clinical, and laboratory characteristics of the studied patients.

\begin{tabular}{|c|c|c|c|}
\hline \multirow{2}{*}{ Characteristics } & Cirrhosis ( $\mathbf{n}=\mathbf{1 7})$ & No-cirrhosis ( $\mathbf{n}=\mathbf{5 1})$ & P value \\
\hline Age (years) & $10.12 \pm 2.8$ & $7.89 \pm 3.72$ & 0.019 \\
\hline Female n (\%) & $14(82.4)$ & $28(54.9)$ & 0.044 \\
\hline Jaundice & $13(76.5)$ & $36(70.6)$ & 0.64 \\
\hline Liver (US) & & & $17(33.3)$ \\
\hline Normal & $5(29.4)$ & $28(54.9)$ & $6(11.8)$ \\
\hline Enlarged & $5(41.2)$ & $36(70.6)$ & 0.225 \\
\hline Shrunken & $16(94.1)$ & $2(3.9)$ & 0.048 \\
\hline Splenomegaly (US) & $2(11.8)$ & $4.74 \pm 5.44$ & 0.258 \\
\hline Ascites (US) & $5.81 \pm 4.11$ & & 0.085 \\
\hline
\end{tabular}




\section{Advanced Research in Gastroenterology \& Hepatology}

\begin{tabular}{|c|c|c|c|}
\hline Direct bilirubin (mg/dl) & $3.89 \pm 2.89$ & $3.19 \pm 4.01$ & 0.154 \\
\hline Alanine transaminase (U/L) & $249.71 \pm 182.02$ & $327.06 \pm 325.74$ & 0.687 \\
\hline Aspartate transaminase (U/L) & $293.53 \pm 334.49$ & $298.9 \pm 299.96$ & 0.039 \\
\hline Albumin (g/dl) & $3.01 \pm 0.49$ & $251.44 \pm 153.37$ & 0.185 \\
\hline Alkaline phosphatase (U/L) & $216.75 \pm 141.78$ & $97.66 \pm 89.29$ & 0.309 \\
\hline gammaglutamyl transpeptidase & $71.44 \pm 58.46$ & $14.11 \pm 1.87$ & 0.04 \\
\hline Prothrombin time (second) & $15.03 \pm 1.85$ & $10.88 \pm 1.41$ & 0.173 \\
\hline Hemoglobin (gm/dl) & $10.38 \pm 1.3$ & $7.95 \pm 3.23$ & 0.066 \\
\hline White blood cells $\left(\mathrm{x} 10^{3} / \mathrm{mm}^{3}\right)$ & $6.08 \pm 2.1$ & $257.63 \pm 117.15$ & 0.001 \\
\hline Platelets (x10 $/ \mathrm{mm}^{3}$ ) & $152.06 \pm 54.85$ & & \\
\hline
\end{tabular}

Table 3: Serological markers of autoimmunity in the studied patients.

\begin{tabular}{|c|c|c|c|}
\hline Characteristics & Cirrhosis & No-cirrhosis & P value \\
\hline Gammaglobulins (gm/dl) & $2.99 \pm 1.31$ & $2.32 \pm 1.23$ & 0.027 \\
\hline Anti-nuclear antibody & $6(35.3)$ & $12(23.5)$ & 0.341 \\
\hline Anti-smooth muscle antibody & $15(88.2)$ & $35(68.6)$ & 0.113 \\
\hline Anti-mitochondrial antibody & 0 & 0 & NA \\
\hline $\begin{array}{c}\text { Liver/kidney microsomal } \\
\text { antibody }\end{array}$ & 0 & $1(2.0)$ & 1 \\
\hline
\end{tabular}

\section{Comparison between children with cirrhosis and those} without

Patients who had cirrhosis at presentation in their initial liver biopsy had higher mean age (10.12 years vs. 7.89 years) and were mainly of female sex ( $82.4 \%$ vs. $54.9 \%)$. Splenomegaly was significantly more frequent in those with cirrhosis $(\mathrm{P}=0.048)$. They had significantly lower serum albumin $(\mathrm{P}=0.039)$, longer PT $(\mathrm{P}=0.04)$, lower platelets count $(\mathrm{P}=0.001)$ and higher serum gammaglobulins $(\mathrm{P}=0.027)$ while other studied parameters were comparable in both groups (Tables $2 \& 3$ ). We further determined the relative risk of cirrhosis associated with parameters with significant difference between the two groups. Female sex, splenomegaly, age $\geq$ 9.5 years, albumin $\leq 3 \mathrm{gm} / \mathrm{dl}, \mathrm{PT} \geq 14$ seconds, platelets count $\leq 200$ $\mathrm{x} 10^{3} / \mathrm{mm}^{3}$, and gammaglobulins $>2.26 \mathrm{gm} / \mathrm{dl}$ were associated with higher risk of cirrhosis ranging between 2.1 and 4.9 (Table 4).
Table 4: Relative risk for parameters associated with cirrhosis

\begin{tabular}{|c|c|c|}
\hline Characteristics & cutoff & Relative risk \\
\hline Female sex & -- & 2.89 \\
\hline Splenomegaly & -- & 4.92 \\
\hline Age (year) & $\geq 9.5$ & 2.96 \\
\hline Albumin $(\mathrm{gm} / \mathrm{dl})$ & $\leq 3.0$ & 2.87 \\
\hline Prothrombin time $(\mathrm{second})$ & $\geq 14.0$ & 2.19 \\
\hline Platelets $\left(\mathrm{x} 10^{3} / \mathrm{mm}^{3}\right)$ & $<200$ & 2.32 \\
\hline Gammaglobulins $(\mathrm{gm} / \mathrm{dl})$ & $>2.26$ & 2.28 \\
\hline
\end{tabular}

\section{Discussion}

Despite the availability of effective treatment, $\mathrm{AIH}$ is not a benign condition. Generally, a high incidence of cirrhosis at diagnosis in children with AIH has been reported in a number of case series [16-18]. The current study is concerned with risk factors associated with presence of cirrhosis at the initial diagnosis of AIH.

We found that older age and female sex were significantly associated with cirrhosis with a relative risk of 2.96 and 2.89 respectively. The higher risk of cirrhosis with older age may be related to the duration of the disease. This is difficult to ascertain as the exact start-time of the disease can not be identified and the disease can start and continue for a considerable time before manifesting [9]. Another possibility is the adolescence-associated hormonal changes. It was reported that a flare of pre-existing disease may occur immediately before or at the age of puberty especially in females [19]. In accordance with other reports [20,21], The current study showed a female preponderance with female: male ratio of 2.6:1. Observations suggest that children and adolescents (age $\leq 20$ years) with AIH may have an aggressive phenotype, and may require a more aggressive management strategy compared to adults (Age $>20$ years). These findings may also reflect differences of immune responses in different age groups [22]. 
In the current study, splenomegaly was significantly higher in those with cirrhosis ( $94.1 \%$ vs. $70.6 \%)$ compared to those without cirrhosis. Those with splenomegaly at presentation have a relative risk of cirrhosis 4.92 times higher than those without splenomegaly. This finding is logical as advanced fibrosis and cirrhosis leads to portal hypertension and its complications. Portal hypertension usually is diagnosed in children with liver disease when splenomegaly and/or evidence of portal-systemic collaterals are found during a physical examination or on abdominal US [23].

According to the laboratory parameters in this study, lower serum albumin $(<3 \mathrm{~g} / \mathrm{dl})$, lower platelet count $\left(<200 \times 10^{3} / \mathrm{mm}^{3}\right)$ and longer PT ( $\geq 14$ seconds) were significantly associated with cirrhosis with a relative risk of 2.87, 2.32 and 2.19 respectively. In hand with our findings, Ngu et al. [22] reported that serum albumin $<3.6 \mathrm{~g} /$ dl $(\mathrm{P}<0.01)$, platelet $<150 \times 10^{3} / \mathrm{mm}^{3}(\mathrm{P}<0.01)$, and international normalized ratio $>1.2(\mathrm{P}<0.01)$ were significant predictors for advanced liver fibrosis at diagnosis. These results suggest that patients with cirrhosis should be offered prompt treatment to avoid hepatic decompensation [22-25].

Autoantibodies, represent a hallmark in the diagnosis of $\mathrm{AIH}$, however, neither autoantibody titers at first diagnosis nor autoantibody behavior in the time course of the disease are prognostic markers for AIH. Additionally, autoantibody status is unable to predict immediate outcome after cessation of corticosteroid administration [24,26]. Furthermore, Mehendiratta et al. [2] reported that the main role of autoantibodies is to identify patients with $\mathrm{AIH}$ and form the basis for a classification, also autoantibody status did not correlate with disease severity or histopathologic findings (portal inflammation, piecemeal necrosis, and plasma cell infiltration). In hand with these reports, we found no significant difference between patients with and those without cirrhosis regarding the occurrence of autoantibodies at presentation $(\mathrm{P}>0.05)$.

Contrary to autoantibodies, gammaglobulins were significantly higher in those with cirrhosis $(2.99 \pm 1.31$ vs. $2.32 \pm 1.23 \mathrm{gm} /$ $\mathrm{dl}$; $\mathrm{P}=0.027$ ) and levels higher than $2.28 \mathrm{gm} / \mathrm{dl}$ were associated with higher risk of cirrhosis (relative risk=2.28). The American Association for the Study of Liver Diseases [4] reported that hypergammaglobulinemia $>2$ times the upper limit of normal (ULN) indicate a more aggressive disease. The British Society of Gastroenterology guidelines [27] suggest that globulins $>2 \times \mathrm{ULN}$ is considered as evidence of having moderate to severe inflammation in patients with AIH. Luth et al. [28] reported that gammaglobulin level is one of the parameters that help in treatment monitoring in AIH. Furthermore, Puustinen et al. [29] reported that elevated gammaglobulins is a risk factor for cirrhosis of baseline liver biopsy in $\mathrm{AIH}$.

\section{Conclusion}

Older age, female sex, splenomegaly, lower serum albumin concentration,lower platelets count, higher PT and gammaglobulins were significantly associated with histopathological cirrhosis at diagnosis.

\section{Financial support}

This study was funded by the National Liver Institute, Egypt, without any particular role in the study design, recruitment of individuals, data analysis or the writing of the report.

\section{Disclosure of interest}

The authors declare that they have no conflicts of interest concerning this article.

\section{References}

1. Miyake Y, Yamamoto K (2008) Current status of autoimmune hepatitis in Japan. Acta Med Okayama 64(2): 217-226.

2. Mehendiratta V, Mitroo P, Bombonati A, Navarro VJ, Rossi S, et al. (2009) Serologic markers do not predict histologic severity or response to treatment in patients with autoimmune hepatitis. Clin Gastroenterol Hepatol 7(1): 98-103.

3. Hennes EM, Zeniya M, Czaja AJ, Pares A, Dalekos GN, et al. (2008) Simplified criteria for the diagnosis of autoimmune hepatitis. Hepatology 48(1): 169-176.

4. Manns MP, Czaja AJ, Gorham JD, Krawitt EL, Mieli-Vergani G, et al. (2010) Diagnosis and management of autoimmune hepatitis. Hepatology 51(6): 2193-2213.

5. Vierling JM (2012) Diagnosis and Treatment of Autoimmune Hepatitis. Current Gastroenterology Reports 14(1): 25-36.

6. Czaja AJ (2013) Challenges in the diagnosis and management of autoimmune hepatitis. Canadian Journal of Gastroenterology 27(9): 531-539.

7. Christen U, Hintermann E (2016) Immunopathogenic Mechanisms of Autoimmune Hepatitis: How Much Do We Know from Animal Models? International Journal of Molecular Sciences 17(12): 2007.

8. Geller SA (2014) Autoimmune hepatitis: Histopathology. Clinical Liver Disease 3(2): 19-23.

9. Lohse AW, Mieli-Vergani G (2011) Autoimmune hepatitis. Journal of Hepatology 55(1): 171-182.

10. Czaja AJ (2010) Difficult treatment decisions in autoimmune hepatitis. World Journal of Gastroenterology WJG 16(8): 934-947.

11. Czaja AJ (2009) Rapidity of treatment response and outcome in type 1 autoimmune hepatitis. Journal of Hepatology 51(1): 161-167.

12. Al-Chalabi T, Underhill JA, Portmann BC, McFarlane IG, Heneghan MA (2008) Impact of gender on the long-term outcome and survival of patients with autoimmune hepatitis. Journal of Hepatology 48(1): 140147.

13. Feld JJ, Dinh H, Arenovich T, Marcus VA, Wanless IR, et al. (2005) Autoimmune hepatitis: Effect of symptoms and cirrhosis on natural history and outcome. Hepatology 42(1): 53-62.

14. Alvarez F, Berg PA, Bianchi FB, Bianchi L, Burroughs AK, et al. (1999) International Autoimmune Hepatitis Group Report: review of criteria for diagnosis of autoimmune hepatitis. J Hepatol 31(5): 929-938.

15. Ishak K, Baptista A, Bianchi L, Callea F, De Groote J, et al. (1995) Histological grading and staging of chronic hepatitis. J Hepatol 22(6): 696-699.

16. Vitfell-Pedersen J, Jørgensen MH, Müller K, Heilmann C (2012) Autoimmune Hepatitis in Children in Eastern Denmark. Journal of Pediatric Gastroenterology and Nutrition 55(4): 376-379.

17. Seo S, Toutounjian R, Conrad A, Blatt L, Tong MJ (2008) Favorable outcomes of autoimmune hepatitis in a community clinic setting. Journal of Gastroenterology and Hepatology 23(9): 1410-1414. 
18. Gregorio GV, Portmann B, Reid F, Donaldson PT, Doherty DG, et al. (1997) Autoimmune hepatitis in childhood. A 20 year survey, Hepatology 25.

19. Mieli-Vergani G, Vergani D (2008) Autoimmune paediatric liver disease. World Journal of Gastroenterology WJG 14(21): 3360-3367.

20. Manns MP, Taubert R (2014) Treatment of autoimmune hepatitis. Clinical Liver Disease 3(1): 15-17.

21. Liberal R, Grant CR, Mieli-Vergani G, and Vergani D (2013) Autoimmune hepatitis: a comprehensive review. Journal of autoimmunity 41: 126139

22. Ngu JH, Gearry RB, Frampton CM, Stedman CAM (2013) Predictors of poor outcome in patients $\mathrm{w}$ ith autoimmune hepatitis: A populationbased study. Hepatology 57(6): 2399-2406.

23. Ling SC (2012) Portal hypertension in children. Clinical Liver Disease 1(5): 139-142.

24. Strassburg CP, Manns MP (2002) Autoantibodies and Autoantigens in Autoimmune Hepatitis. Semin Liver Dis 22(04): 339-352.

This work is licensed under Creative

Commons Attribution 4.0 License

DOI: 10.19080/ARGH.2017.04.555641
25. Dalekos GN, Zachou K, Liaskos C, Gatselis N (2002) Autoantibodies and defined target autoantigens in autoimmune hepatitis: an overview. European Journal of Internal Medicine 13(5): 293-303.

26. Czaja AJ (1999) Behavior and significance of autoantibodies in type 1 autoimmune hepatitis. Journal of Hepatology 30(3): 394-401.

27. Gleeson D, Heneghan MA (2011) British Society of Gastroenterology (BSG) guidelines for management of autoimmune hepatitis. Gut 60(12): 1611-1629.

28. Lüth S, Herkel J, Kanzler S, Frenzel C, Galle PR, et al. (2008) Serologic markers compared with liver biopsy for monitoring disease activity in autoimmune hepatitis, Journal of clinical gastroenterology 42(8): 926 930.

29. Puustinen L, Boyd S, Mustonen H, Arkkila P, Arola J, et al. (2017) Prognostic value of clinical variables and liver histology for development of fibrosis and cirrhosis in autoimmune hepatitis. Scandinavian Journal of Gastroenterology 52(3): 321-327.

\section{Your next submission with Juniper Publishers will reach you the below assets}

- Quality Editorial service

- Swift Peer Review

- Reprints availability

- E-prints Service

- Manuscript Podcast for convenient understanding

- Global attainment for your research

- Manuscript accessibility in different formats

( Pdf, E-pub, Full Text, Audio)

- Unceasing customer service

Track the below URL for one-step submission https://juniperpublishers.com/online-submission.php 